Fifth International Conference on Sustainable Construction Materials and

Technologies. http://www.claisse.info/Proceedings.htm

\title{
ASSESSMENT OF THE EFFECTIVENESS OF BUTLER- VOLMER EQUATION TO PREDICT CORROSION RATE IN CATHODICALLY PROTECTED STRUCTURES
}

\author{
Arpit Goyal ${ }^{1}$ Homayoon Sadeghi Pouya ${ }^{2}$ and Eshmaiel Ganjian ${ }^{3}$ \\ ${ }^{1} \mathrm{PhD}$ scholar, Centre for Built and Natural Environment, Coventry University, \\ Coventry, CV12JH, United Kingdom, Email: goyala4@uni.coventry.ac.uk \\ ${ }^{2}$ Research fellow, Faculty Research Centre for Built \& Natural Environment, Coventry \\ University, Coventry, CV12JH, United Kingdom, Email: \\ H.Sadeghipouya@coventry.ac.uk \\ ${ }^{3}$ Professor, School of Energy, Construction and Environment, Centre for Built \& \\ Natural Environment, Coventry University, Coventry, CV1 2JH, United Kingdom, \\ Email: E.Ganjian@coventry.ac.uk
}

\begin{abstract}
Various reinforced concrete structure around the world, such as bridges are exposed to aggressive chloride environment, hence, start to corrode after short service period. The main reason for the deterioration of these structures is corrosion of steel reinforcement due to chlorides. Poor quality concrete and low cover are contributory factors. The cost of repairing or replacing the deteriorated structure has become the major concern for the asset owners. One of the most successful and substantiated techniques of protecting structure from corrosion is cathodic protection $(\mathrm{CP})$. The BS EN ISO 12696 performance criteria followed for monitoring CP efficiency is evolved from the experimental analysis and may not be always correct. This paper suggests an improved method for monitoring corrosion rate through Butler Volmer equation using the polarization data. This method has been applied to one year $\mathrm{CP}$ monitoring data from a viaduct site. It was observed that corrosion rate was reducing with time, showing the effectiveness of $\mathrm{CP}$ to protect the steel in structure. Prediction of corrosion rate of the steel from potential shift forms the basis for the improved $\mathrm{CP}$ performance criterion for reinforced concrete structures. Information about the actual corrosion rate would be beneficial to predict the true state of steel reinforcement and accordingly apply a suitable repair technique to extend the service life of RC structures.
\end{abstract}

Keywords: Corrosion, Cathodic Protection, Potential Shift, Butler Volmer equation, Corrosion Rate 


\section{INTRODUCTION}

Corrosion of steel bars is one of the biggest durability issue for reinforced concrete structures. Out of various preventive techniques, cathodic protection $(\mathrm{CP})$ technique has been shown to be highly effective to prevent corrosion of steel in chloride contaminated concrete (Goyal et al., 2018). The technique is based upon delivering required DC current to the steel to be protected to shift its potential to negative direction such that corrosion rate is either significantly reduced or steel reaches its passivation (Goyal et al., 2019; Marcassoli et al., 2015).

The most common protection criteria used to monitor the performance of CP system is to check $100 \mathrm{mV}$ potential decay following interruption of the potential current (Atkins and Macdonald, 2010.; Eichler et al., 2009; Funahashi and Bushman, 1991; Glass, 1999; Gummow, 2007). The magnitude of the potential decay required is usually $100 \mathrm{mV}$. This is referred to as $100 \mathrm{mV}$ decay criteria. This method is recommended by BS EN ISO 12696:2016 (British Standards Institution, 2016).

Most of the structures in natural environment, cannot achieve thermodynamic reversibility and immunity (Barlo, 2001). Thus, corrosion control is achieved by reducing the corrosion process kinetics (i.e. corrosion rate) to sufficiently low levels that corrosion appears to be stopped. $100 \mathrm{mV}$ polarization criteria achieves corrosion control in this way (Barlo, 2001). However, this method was evolved mainly from experimental basis. The disadvantage of this method is that it cannot be used with mixed metal structures (Barlo, 2001; Gummow, 2007). Moreover, it is not considered valid when elevated temperature or sulphate reducing bacteria are present (Khosravi and Ghafourian, 2013, 2012). Furthermore, some researchers has challenged the adequacy of $100 \mathrm{mV}$ criterion and the theoretical basis for its use is still subject to investigation (Glass et al., 1997).

This paper suggests an improved method for monitoring corrosion rate through Butler Volmer equation using the polarization data, which forms the basis for monitoring efficacy of CP structure. The modified method was used to evaluate one year monitoring data collected from a cathodically protected 20-span viaduct in Peterborough.

\section{NEW APPROACH FOR CP PERFORMANCE ASSESSMENT}

In 1950, the Butler Volmner equation, given in eq (1), was simplified by assuming potential shift was small $(10-20 \mathrm{mV})$ and forms the basis of most widely used linear polarization resistance (LPR) method used to measure corrosion rate of steel. The simplified butler Volmer equation is given in eq (2).

$$
i=i^{o}\left\{\exp \left(\frac{-\alpha_{c} F \eta}{R T}\right)-\exp \left(\frac{\alpha_{a} F \eta}{R T}\right)\right\}
$$


Where $\eta=E-e_{e}$ i.e. the difference between the potential, $E$, when a net current flows through electrochemical cell and reversible half-cell potential, $e_{e} ; i^{o}\left(\mathrm{~A} / \mathrm{m}^{2}\right)$ is exchange current density; $i$ is current density; $\mathrm{R}$ is Gas Constant; $F$ is Faraday's Constant; $T$ is Absolute Temperature and $\alpha_{c}$ is the fraction of total energy that decreases the energy barrier for cathodic reactions and $\alpha_{a}$ is the fraction of total energy that increases the energy barrier for anodic reactions (Popov, 2015).

$$
i=-i^{\mathrm{o}} \frac{n F \eta}{R T}=\frac{B}{R_{p}}
$$

Where $R_{p}=\frac{R T}{n F i^{\circ}}$, is polarization resistance and $B$ is Stern Geary constant. The value of Stern Geary Constant i.e. $B\left(B=\frac{\beta a * \beta c}{2.303(\beta a+\beta c)}\right)$ is typically used as $26 \mathrm{mV}$ for an active steel and $52 \mathrm{mV}$ for a passive steel (Song and Saraswathy, 2007).

Since, this method is only limited to $10-20 \mathrm{mV}$ shift, it's not applicable for monitoring $\mathrm{CP}$ performance. Hence, Butler Volmer equation was improved as given in eq (3), which can be used for CP performance assessment. The detailed analysis of the method is given in author's previous work (Goyal et al., 2019).

$$
i_{\text {app }}=i_{\text {corr }}\left\{\exp \left(\frac{2.3 \Delta E}{\beta_{\mathrm{c}}}\right)-\exp \left(\frac{-2.3 \Delta E}{\beta_{\mathrm{a}}}\right)\right\}
$$

Where $i_{a p p}$ is the applied current density, $i_{c o r r}$ is the corrosion rate, $\Delta E$ is the potential shift and $\beta_{a}$ and $\beta_{c}$ are constants.

The method uses polarization results from $\mathrm{CP}$ monitoring data, in which the steel/concrete/electrode potential shift, and applied current density are the major parameters. Moreover, value of cathodic tafel slope $\left(\beta_{c}\right)$ plays a major role. The tafel slopes are obtained by plotting the change in steel/concrete/electrode potential against the logarithm of the applied current after each polarization. The slope of the curve will give an indication of the cathodic tafel slope $\left(\beta_{c}\right)$. Anodic tafel slope $\left(\beta_{a}\right)$ has minimal effect on the corrosion rate prediction and thus taken as constant of $120 \mathrm{mV}$, which is used while LPR monitoring.

\section{BRIEF DESCRIPTION OF THE STRUCTURE AND ANODE SYSTEMS}

The structure selected for monitoring was 20-span viaduct in Peterborough. Each span was approximately $16 \mathrm{~m}$. The structure comprises 6 leaf piers and $14 \mathrm{~T}$ shape piers. Cathodic protection was applied to the structure in 2008 as part a major refurbishment scheme to prevent RC elements from further deterioration and reinforcement corrosion. For the present analysis, 3 no. piers were selected. 


\section{The Anode System}

Three types of anodes were used for installation of CP to the piers i.e. (a) De Nora LIDA 19mm diameter MMO/Ti based discrete anodes, (b) Elgard 150 mesh anodes, and (c) Elgard 100 ribbon mesh anode. Pier 1 and 2 have similar geometry and are protected by installing rows of ribbon anodes on all four sides of a column at a spacing of 300mm (Figure 1 (a) and (b)). The bearing shelf is protected by discrete anodes with ribbon anodes on soffit and sides (Figure1 (c)). Each pier is divided to a number of zones as shown in Figures 1. For present analysis 4 ribbon anode zones (two from column and 2 from crossbeam) and 1 discrete anode zone were selected for pier 1 and 2. Data were collected remotely using a dedicated software and downloaded to an offsite computer in an Excel file format.

Pier 3 is leaf pier and has discrete anode zone at the top and mesh anode zone on the side (Figure 2). For analysis, one discrete anode zone and one mesh anode zone were selected. Details of all the CP zones and anode system are given in Table 1.

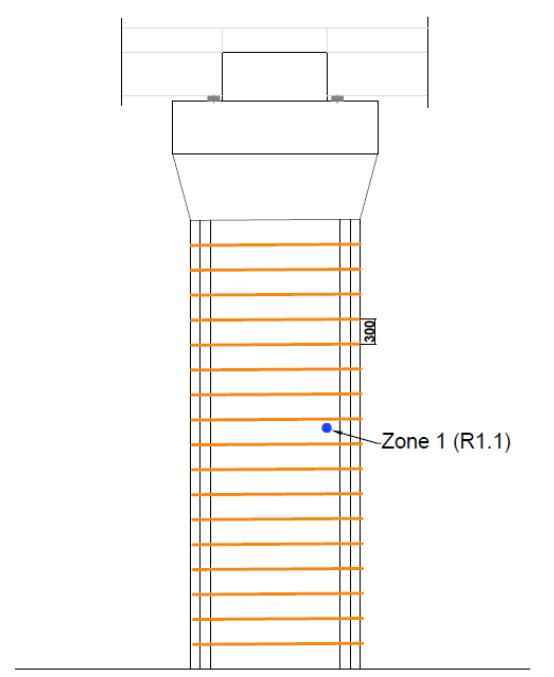

(a) North Elevation Column: Zone 1 (North and South combine)

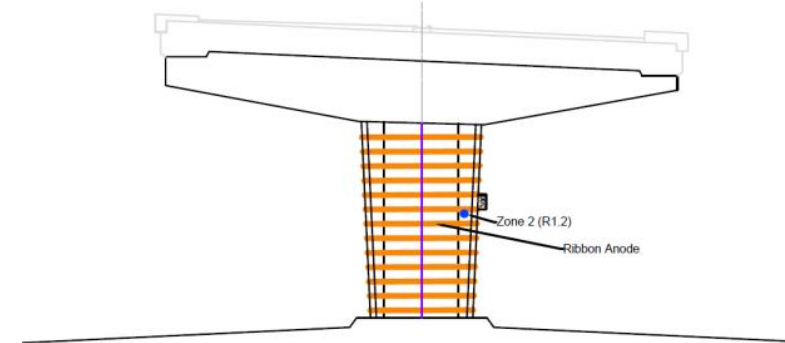

(b) West Elevation Column: Zone 2 (West and East combine)

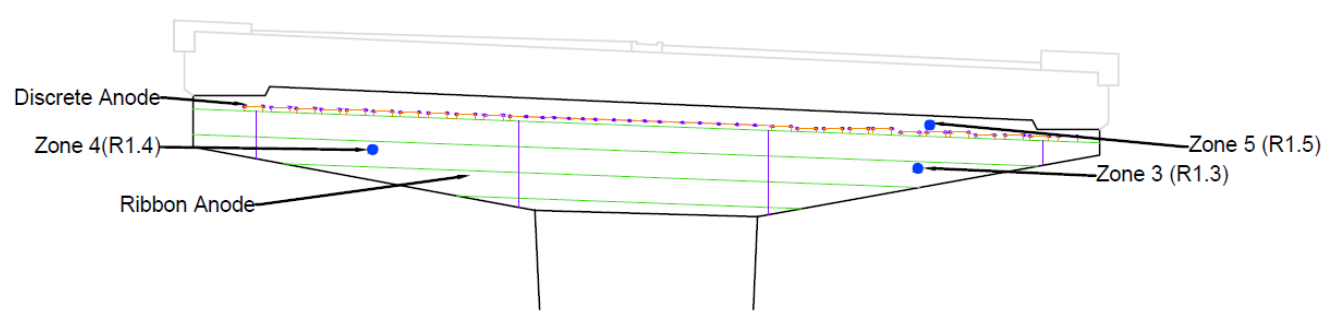

(c) Crossbeam: Zone 3 (West), Zone 4 (East), Zone 5 (West and East combine) 
Figure 1: Pier 1 showing anode placement (a) North elevation (b) West elevation (c) Crossbeam

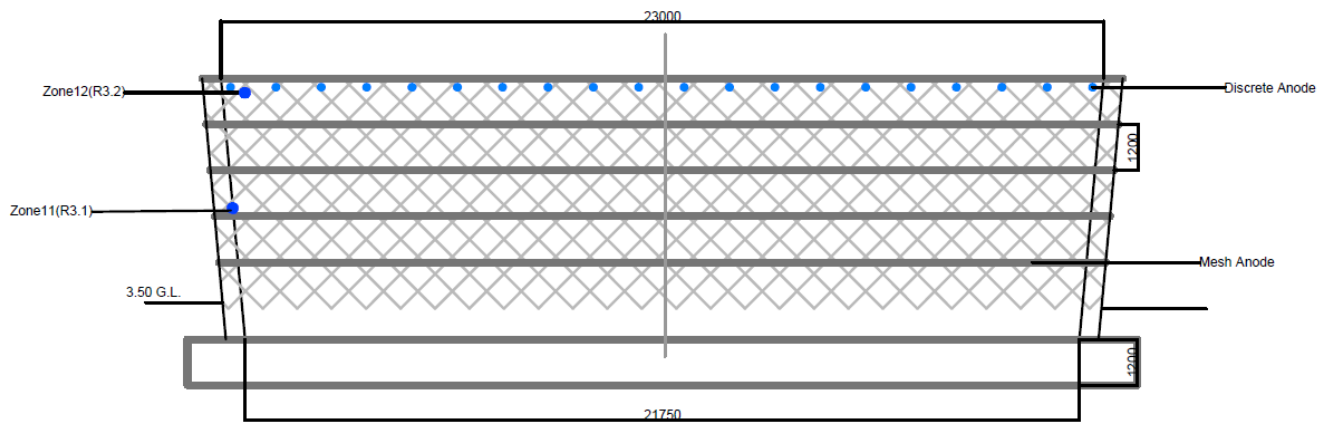

Figure 2: Pier 3 showing anode placement: Zone 11 and 12 (West and east side combine)

Table 1: Details of the selected anodes

\begin{tabular}{cccc}
\hline Pier & Zone & Reference Electrode & Anode \\
\hline Pier 1 & 1 & R1.1 & Ribbon \\
& 2 & R1.2 & Ribbon \\
& 3 & R1.3 & Ribbon \\
& 4 & R1.4 & Ribbon \\
& 5 & R1.5 & Discrete anode \\
\hline Pier 2 & 6 & R2.1 & Ribbon \\
& 7 & R2.2 & Ribbon \\
& 8 & R2.3 & Ribbon \\
& 9 & R2.4 & Ribbon \\
& 10 & R2.5 & Discrete anode \\
\hline Pier 3 & 11 & R3.1 & Discrete anode \\
& 12 & R3.2
\end{tabular}

The site images of the installed or during installation of various anodes are shown in Figure 3. 

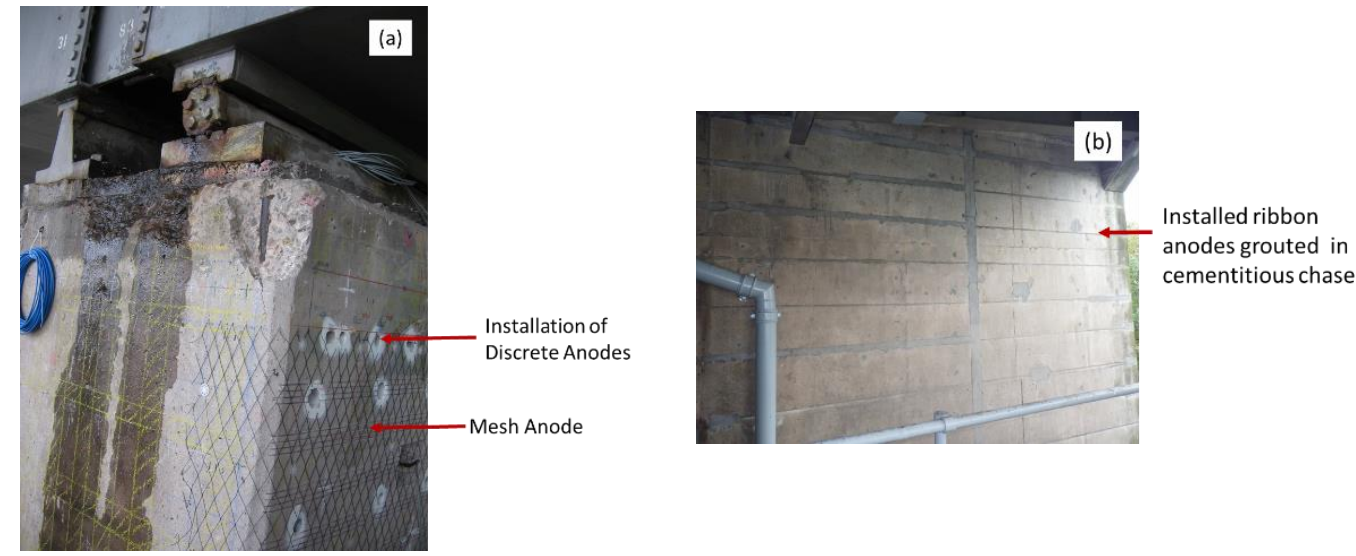

Figure 3: Site images showing anode installation (a) Pier 3 (b) Pier 1 and 2

\section{ANALYSIS AND DISCUSSION}

\section{CP Monitoring Using $100 \mathrm{mV}$ Decay Criterion}

Individual CP Zones were energised at initial $25 \%$ of their design current density of $15 \mathrm{~mA} / \mathrm{m}^{2}$ and then adjusted over time The polarization behaviour of the anodes zones were observed and analysed after period of 1 month and 1year by automatic preprogrammed switching off the power supply and monitoring steel/concrete 24 hours potential decay. All decay values were measured from instant off potentials with respect to silver/silver chloride reference electrodes. Results are shown in Table 2. All the zones showed at least $100 \mathrm{~m} \mathrm{~V} \mathrm{decay} \mathrm{after} \mathrm{both} 1$ month and 1 year of polarization, thus satisfies the BS EN 12696: 2016 criterion (British Standards Institution, 2016). However, this method only satisfied the standard requirement for performance of the $\mathrm{CP}$ technique and do not provide any information with which or the remaining service life of the structure can be estimated.

Table 2: Polarization results for various zones after 1 month and 1 year

\begin{tabular}{llllll}
\hline Zone & $\begin{array}{l}\text { Reference } \\
\text { Electrode }\end{array}$ & $\begin{array}{l}\text { Potential } \\
\text { shift }(\mathrm{mV}): 1 \\
\text { month }\end{array}$ & $\begin{array}{l}\text { Potential } \\
\text { shift }(\mathrm{mV}): 1 \\
\text { year }\end{array}$ & $\begin{array}{l}\text { 24 h decay } \\
(\mathrm{mV}): 1 \\
\text { month }\end{array}$ & $\begin{array}{l}\text { 24 h decay } \\
(\mathrm{mV}): 1 \text { year }\end{array}$ \\
\hline 1 & R1.1 & -145 & -128 & 160 & 143 \\
2 & R1.2 & -166 & -166 & 198 & 196 \\
3 & R1.3 & -319 & -290 & 301 & 262 \\
4 & R1.4 & -200 & -178 & 254 & 234 \\
5 & R1.5 & -214 & -155 & 235 & 188 \\
6 & R2.1 & -155 & -179 & 159 & 161 \\
7 & R2.2 & -325 & -300 & 215 & 280 \\
8 & R2.3 & -265 & -171 & 282 & 235 \\
9 & R2.4 & -374 & -333 & 274 & 242 \\
10 & R2.5 & -293 & -242 & 268 & 241
\end{tabular}




\begin{tabular}{llllll}
11 & R3.1 & -217 & -224 & 149 & 156 \\
12 & R3.2 & -186 & -163 & 192 & 180 \\
\hline
\end{tabular}

\section{Corrosion Rate Determination from Improved Monitoring Method}

The cathodic tafel slope $\left(\beta_{c}\right)$ is obtained by plotting the change in steel/concrete/electrode potential against the logarithm of the applied current density, as shown in Figure 4. It can be observed that $\beta_{c}$ changes for different zones and is not constant $(120 \mathrm{mV})$ as considered while measuring corrosion rate using LPR on site.

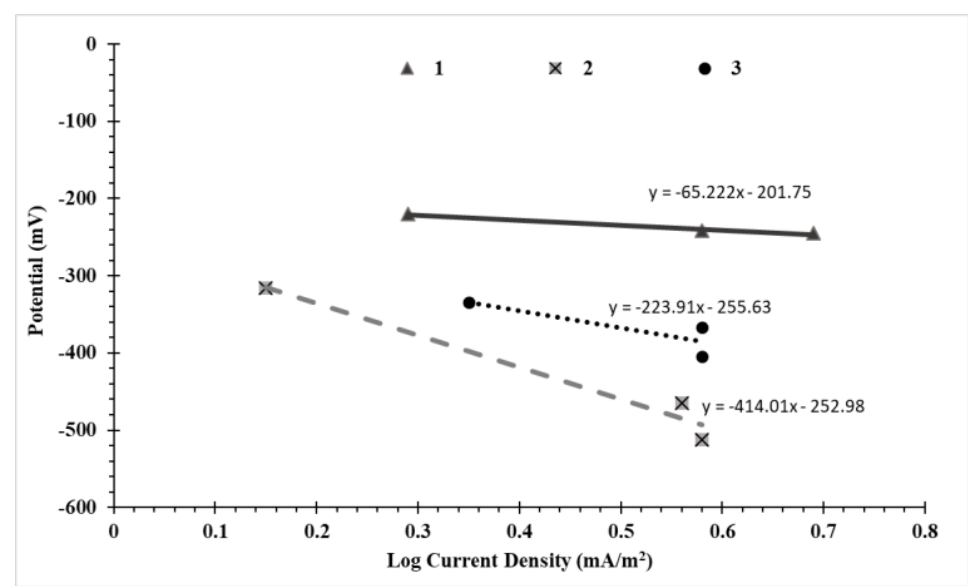

Figure 4: Cathodic Slope prediction from potential current graph

Figure 5 shows corrosion rate calculated using modified Butler Volmer equation (Equation 3) with an assumption of $\beta_{c}$ to be $120 \mathrm{mV}$ (Figure 5(a)) and $\beta_{c}$ obtained from Figure 4 (Figure 5(b)). It can be observed that assuming $\beta_{c}$ to be $120 \mathrm{mV}$ constant gives an underestimation of the corrosion rate. 

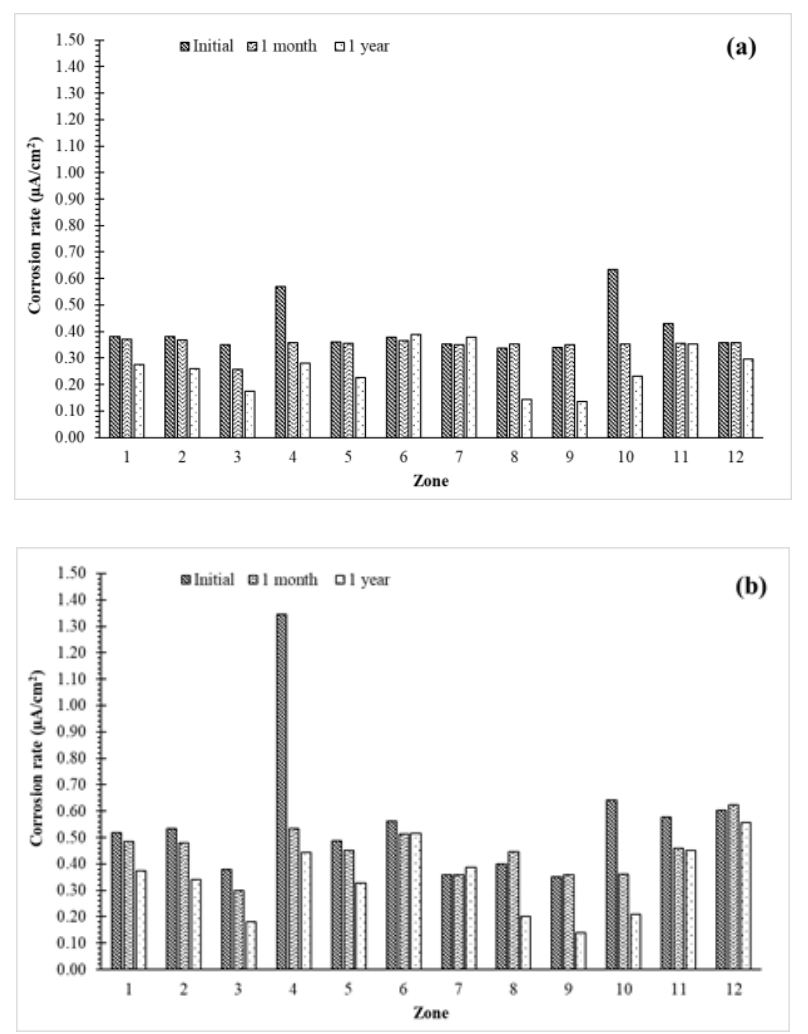

Figure 5: Corrosion rate for different zones considering cathodic tafel slope of (a) $120 \mathrm{mV}$ (b) obtained from cathodic slope prediction (Figure 4)

Performance of individual CP zones are also shown in Figure 6 against published corrosion state as suggested by concrete society (Report, 2004) given in Table 3

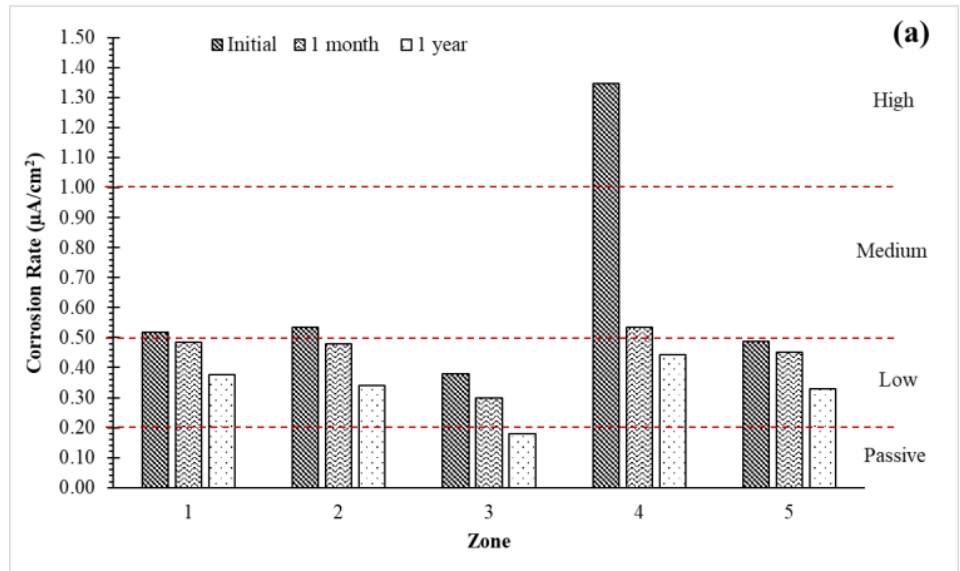



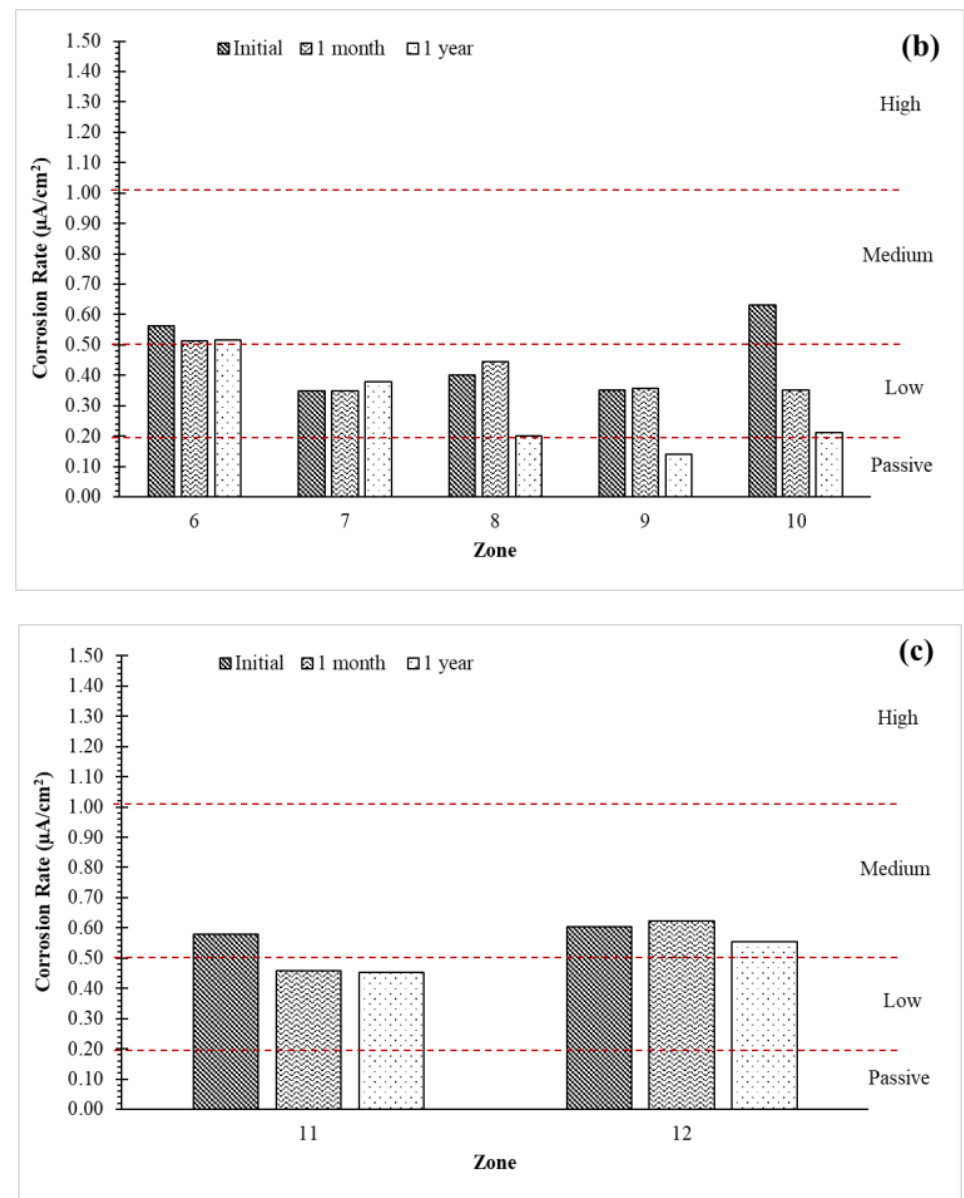

Figure 6: Corrosion rate using suggested method of monitoring for different zones (a) Pier 1 (b) Pier 2 and (c) Pier 3

Table 3: Corrosion current vs. condition of the rebar (Report, 2004)

\begin{tabular}{cl}
\hline Corrosion current $\left(\mathrm{I}_{\text {corr }}\right), \mu \mathrm{A} / \mathrm{cm}^{2}$ & Condition of the rebar/ corrosion rate \\
\hline$<0.1-0.2$ & Passive \\
$0.2-0.5$ & Low to moderate corrosion \\
$0.5-1.0$ & Moderate to high corrosion \\
$>1.0$ & High corrosion \\
\hline
\end{tabular}

It can be observed from Figure 6 that corrosion rate decreases with time for all the zones and piers. Cathodic protection is observed to be highly effective for zones shown in figure 6. For zone 3, 8, 9 and 10 steel moves to passive zone after 1 year of CP application. The largest drop in corrosion rate was observed for zone 8 , where corrosion rate dropped by $67 \%$ moving steel from highly corrosive to low corrosion state. This shows the effectiveness of $\mathrm{CP}$ for pier 1 and 2. 
Moreover, for pier 3, steel does not show a much drop in corrosion rate and steel remains in its initial corrosion state. Thus, requires longer protection or increased current output for the zones.

Comparing the results from two different analysing methods, it can be clearly observed that suggested improved method gives the better indication of the efficacy of the preventive technique. $100 \mathrm{mV}$ decay criterion shows that for each zone prevention has been achieved, however that is not true seeing the corrosion rate of steel from the modified method.

\section{CONCLUSION}

The commonly used $100 \mathrm{mV}$ decay criteria is evolved from experimental investigation and may not always be accurate. Suggested method of monitoring by using potential shift data obtained from polarization results by applying a known current density can be used to get an estimation of the corrosion state of steel and the efficiency of the CP using Butler Volmer equation. A decrease in the corrosion rate also indicates that $\mathrm{CP}$ is providing effective protection.

Moreover, corrosion rate estimation is highly sensitive to value of cathodic tafel slope. Corrosion rate estimated from analysing the field data assuming cathodic tafel slope to be $120 \mathrm{mV}$ constant gives an underestimation of the corrosion rate. Data obtained from suggested method will be beneficial to structural engineer for structural assessment. Corrosion rate obtained can be used to estimate the capacity of the structure in the long run and estimate the remaining service life.

\section{REFERENCES}

Atkins, C. and McDonald, M. (2010). "Monitoring CP System." CPA Technical Note 17

Barlo, T.J. (2001). "Origin and Validation of the 100 mv Polarization Criterion." In Corrosion 2001, NACE International

British Standards Institution (2016) "Cathodic Protection of Steel in Concrete." BS EN ISO 12696: 2016, London: British Standards Institution

Eichler, T., Isecke, B. and Bäßler, R. (2009). "Investigations on the re-passivation of carbon steel in chloride containing concrete in consequence of cathodic polarisation." Mater. Corros., 60(2), 119-129.

Funahashi, M. and Bushman, J.B. (1991). "Technical Review of 100 mV Polarization Shift Criterion for Reinforcing Steel in Concrete." In Corrosion, NACE International, 47 (5), 376-386

Glass, G.K. (1999). "Technical Note: The 100-mV Potential Decay Cathodic 
Protection Criterion." In Corrosion, NACE International, 55 (3), 286-290

Glass, G.K., Hassanein, A.M. and Buenfeld, N.R (1997). "Monitoring the passivation of steel in concrete induced by cathodic protection." Corros. Sci., 39, 1451-1458,

Goyal, A., Sadeghi, H., Ganjian, E., Omotayo, A. and Khorami, M. (2019). "Predicting the corrosion rate of steel in cathodically protected concrete using potential shift." Constr. Build. Mater., 194, 344-349.

Goyal, A., Sadeghi, H., Eshmaiel, G. and Peter, C. (2018). "A Review of Corrosion and Protection of Steel in Concrete." Arab. J. Sci. Eng., 43(10), 5035-5055.

Gummow, R.A. (2007). "Technical Considerations on the Use of the 100mV Cathodic Polarization Criterion." in Corrosion 2007, NACE International, 7035, 1-11

Khosravi, J. and Ghafourian, S.S.M. (2013). "Using the 100-mV Criterion for Protection of New Structures." in Materials Performance, 52(3), pp.30-35.

Khosravi, J. and Ghafourian, S.S.M. (2012). "100mv Cathodic Protection CriterionUsing Of "Instant-on" Potential in ICCP of New Structures." in Corrosion 2012, NACE International

Marcassoli, P., Bonetti, A., Lazzari, L. and Ormellese, M. (2015). "Modeling of potential distribution of subsea pipeline under cathodic protection by finite element method." Mater. Corros., 66, 619-626.

Popov (2015) Corrosion Engineering: Principles and Solved Problems, first ed., Elservier, Oxford.

Report, C.S.T. (2004) Electrochemical tests for reinforcement corrosion, The Concrete Society technical report 60.

Song, H.W. and Saraswathy, V. (2007). "Corrosion monitoring of reinforced concrete structures-A Review." Int. J. Electrochem. Sci, 2, 1-28. 